\title{
Probability of a great earthquake to recur in the Tokai district, Japan: reevaluation based on newly-developed paleoseismology, plate tectonics, tsunami study, micro-seismicity and geodetic measurements
}

\author{
Tsuneji Rikitake \\ Association for the Development of Earthquake Prediction, 1-5-18 Sarugaku-cho, Chiyoda-ku, Tokyo 101-0064, Japan
}

(Received August 6, 1998; Revised November 24, 1998; Accepted February 17, 1999)

\begin{abstract}
In light of newly-acquired geophysical information about earthquake generation in the Tokai area, Central Japan, where occurrence of a great earthquake of magnitude 8 or so has recently been feared, probabilities of earthquake occurrence in the near future are reevaluated. Much of the data used for evaluation here relies on recently-developed paleoseismology, tsunami study and GPS geodesy.

The new Weibull distribution analysis of recurrence tendency of great earthquakes in the Tokai-Nankai zone indicates that the mean return period of great earthquakes there is estimated as $109 \mathrm{yr}$ with a standard deviation amounting to $33 \mathrm{yr}$. These values do not differ much from those of previous studies (Rikitake, 1976, 1986; Utsu, 1984).

Taking the newly-determined velocities of the motion of Philippine Sea plate at various portions of the TokaiNankai zone into account, the ultimate displacements to rupture at the plate boundary are obtained. A Weibull distribution analysis results in the mean ultimate displacement amounting to $4.70 \mathrm{~m}$ with a standard deviation estimated as $0.86 \mathrm{~m}$. A return period amounting to $117 \mathrm{yr}$ is obtained at the Suruga Bay portion by dividing the mean ultimate displacement by the relative plate velocity.

With the aid of the fault models as determined from the tsunami studies, the increases in the cumulative seismic slips associated with the great earthquakes are examined at various portions of the zone. It appears that a slip-predictable model can better be applied to the occurrence mode of great earthquakes in the zone than a time-predictable model. The crustal strain accumulating over the Tokai area as estimated from the newly-developed geodetic work including the GPS observations is compared to the ultimate strain presumed by the above two models.

The probabilities for a great earthquake to recur in the Tokai district are then estimated with the aid of the Weibull analysis parameters obtained for the four cases discussed in the above. All the probabilities evaluated for the four cases take on values ranging 35-45 percent for a ten-year period following the year 2000.
\end{abstract}

\section{Introduction}

Recurrence of great earthquakes off the Tokai-Nankai area, the Pacific coast of central and southwestern Japan, with a return period of 100-150 years is one of the most conspicuous features of seismic activity in Japan. As no such earthquake occurred in the Suruga Bay area, the eastern-most portion of the earthquake zone, since the Ansei Tokai earthquake ( $M=$ 8.4 ) in 1854 , it has recently been feared that an earthquake having a magnitude of 8 or thereabout might hit there sooner or later and probably sooner.

Accordingly, every effort toward predicting the occurrence of such an earthquake has been made on the nation-wide scale. The writer (Rikitake, 1976), who analyzed the recurrence tendency of great earthquakes as reported in Japan's history, estimated the probability of earthquake occurrence there in the near future. He also evaluated the probability based on the ultimate strain of the earth's crust and strain accumulation inferred from geodetic surveys (Rikitake, 1977). The probabilities thus obtained were surprisingly high reaching 30-40 percent for a ten-year period from around 1980.

Copy right (C) The Society of Geomagnetism and Earth, Planetary and Space Sciences (SGEPSS); The Seismological Society of Japan; The Volcanological Society of Japan; The Geodetic Society of Japan; The Japanese Society for Planetary Sciences.
It is therefore not surprising that all sorts of geophysical and geochemical observation networks have been developed in the Tokai area in the hope of monitoring anomalies that might suggest occurrence of a great earthquake there. These observations have led us to obtain many useful results for looking at the microseismicity there, the existence of a tightly-coupled portion between the land and sea plates, and almost day-by-day fluctuations of plate motions as disclosed by GPS observations.

On the other hand, paleoseismological studies on ground liquefaction, that became popular in recent years, disclosed occurrence times of great earthquakes in the Tokai and Nankai areas in the past, and so the history of those earthquakes is brought to light more clearly.

Plate tectonics in and around the Japan Islands also reached a more matured state, so that the relative velocities at the Eurasian-Philippine Sea plate boundary, that agrees with the Suruga-Nankai trough, can become evaluated a little more accurately in recent years (Seno et al., 1993).

Faulting models of great earthquakes in the past have recently been studied intensively, not only from the seismometric standpoint, but also by tsunami study, the latter being powerfully applied to the study of source mechanism of his- 


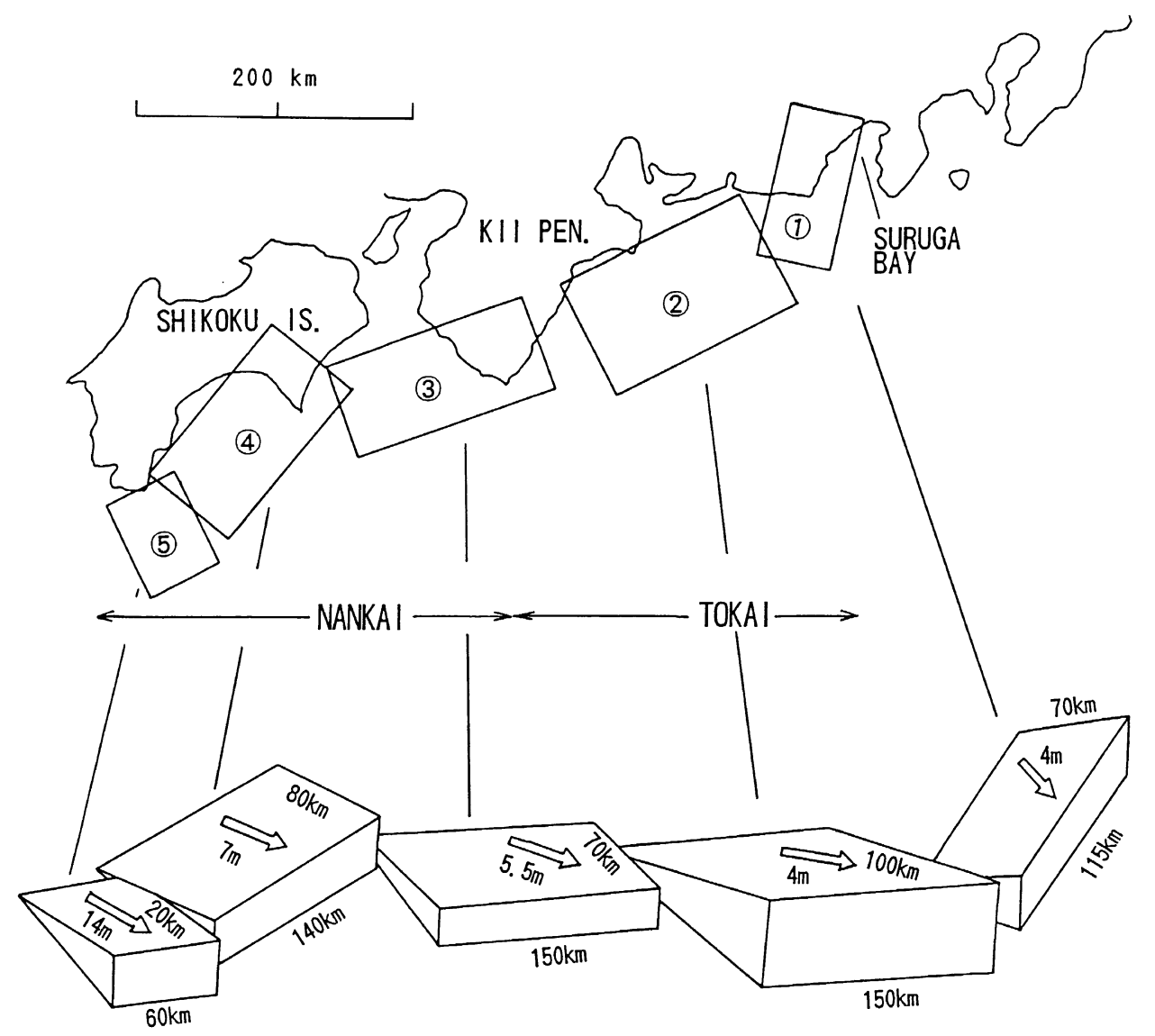

Fig. 1. Seismic fault model for the 1707 Hoei earthquake of $M=8.4$ as obtained from the tsunami study by Aida (1981b). Dimensions of the faults along with the fault slips are shown for the 5 segments considered.

torical earthquakes in the Tokai-Nankai area which cannot be studied by seismological means (Aida, 1979, 1981a,b).

Theoretical insight related to the recurrence mode of great earthquakes in the area concerned has currently been advanced by introducing quasi-characteristic models such as time-predictable (TPM) and slip-predictable ones (SPM).

In light of the above-mentioned development of various geophysical approaches, it is intended in this paper to reevaluate the probability of a great earthquake to recur in the Suruga Bay and off the Tokai area with the aid of newlyobtained data.

\section{Probabilities Due to Simple Recurrence Model}

In the writer's previous study (Rikitake, 1976), it is assumed that the 1498 earthquake, that gave rise to tremendous damage in the Tokai area, did not affect much the Nankai area because no historical documents were available in relation to the damage in the Nankai area caused by the earthquake. Such a view had to be altered drastically taking the ground liquefaction evidence in the Nankai area, reported by Sangawa (1990, 1992) into account.

As can be seen in Fig. 1, that shows the fault models of the 1707 Hoei earthquake $(M=8.4)$ presented by Aida (1981b) based on the analysis of tsunamis associated with the earthquake, the Suruga-Nankai trough seismic zone can be divided into a number of segments. It now seems possible to see the occurrence pattern in each fault segment along the trough throughout Japan's history covering 1000 years or so. In Table 1 are shown the occurrence times of faulting that gave rise to great earthquakes originating in respective segments based on historical documents and paleoearthquake studies. In the previous analysis (Rikitake, 1976), it was only possible to divide the zone into the Nankai and Tokai segments, so that it may be said that the occurrence model of great earthquakes along the Suruga-Nankai trough is substantially improved.

We see in Table 1 that great earthquakes tended to recur with a 100-150 year interval over the 13-20th century period and that the apparent return period becomes roughly doubled before that period. It is not known whether or not such a change in the return period is true because it is possible to have no historical report in such early days. The following statistics is made, therefore, only on the data since the 12th century. Segment 5 shown in Fig. 1 is excluded from Table 1 and so from the following statistics because only one faulting in 1707 is reported at the western-most portion of the zone. Although there are only two earthquakes for segment 1 as seen in Table 1, it is in this paper assumed that the style of earthquake generation there is the same as that in other segments.

Based on Table 1, the frequency histogram of return period is drawn as can be seen in Fig. 2(a) and then the frequency distribution is subjected to a Weibull distribution analysis in a 
Table 1. Great earthquakes in the Tokai-Nankai zone. Open circles show firmly established epochs in history. Solid circles are suggested by ground liquefaction evidence. Those with parentheses are a little less reliable.

\begin{tabular}{|c|c|c|c|c|c|c|c|c|c|}
\hline \multicolumn{2}{|c|}{ Earthquake } & \multicolumn{4}{|c|}{ Tokai zone } & \multicolumn{4}{|c|}{ Nankai zone } \\
\hline \multirow{2}{*}{ Year } & \multirow{2}{*}{ Magnitude } & \multicolumn{2}{|c|}{$\begin{array}{l}\text { Suruga Bay } \\
\text { (Segment 1) }\end{array}$} & \multicolumn{2}{|c|}{$\begin{array}{c}\text { Off Tokai } \\
\text { (Segment 2) }\end{array}$} & \multicolumn{2}{|c|}{$\begin{array}{l}\text { Off Kii Pen. } \\
\text { (Segment } 3 \text { ) }\end{array}$} & \multicolumn{2}{|c|}{$\begin{array}{l}\text { Off Shikoku Is. } \\
\text { (Segment 4) }\end{array}$} \\
\hline & & Evidence & $\begin{array}{c}\text { Interval } \\
(\mathrm{yr})\end{array}$ & Evidence & $\begin{array}{c}\text { Interval } \\
(\mathrm{yr})\end{array}$ & Evidence & $\begin{array}{c}\text { Interval } \\
(\mathrm{yr})\end{array}$ & Evidence & $\begin{array}{c}\text { Interval } \\
(\mathrm{yr})\end{array}$ \\
\hline 684 & 8.3 & & & $(\bullet)$ & & $(\bullet)$ & & 0 & \\
\hline 887 & $8 \sim 8.5$ & & & & & & & 0 & \\
\hline 1096 & $8 \sim 8.5$ & & & 0 & & & & & \\
\hline 1099 & $8 \sim 8.3$ & & & & & & & $\bigcirc$ & \\
\hline 1361 & $8.3 \sim 8.5$ & & & & & & & 0 & \\
\hline & & & & & & & & & 137 \\
\hline 1498 & $8.2 \sim 8.4$ & & \multirow{6}{*}{147} & 0 & 107 & $\bigcirc$ & 107 & $\bullet$ & 107 \\
\hline 1605 & 7.9 & & & $\bigcirc$ & 102 & $\bigcirc$ & 102 & $\bigcirc$ & 102 \\
\hline 1707 & 8.4 & $\bigcirc$ & & $\bigcirc$ & 102 & $\bigcirc$ & 102 & $\bigcirc$ & 102 \\
\hline 1854 & 8.4 & $\bigcirc$ & & 0 & $14 /$ & 0 & 147 & 0 & 147 \\
\hline 1944 & 7.9 & & & 0 & & & 92 & & 92 \\
\hline 1946 & 8.0 & & & & & 0 & & 0 & \\
\hline
\end{tabular}

manner similar to that in the previous paper (Rikitake, 1976).

Let us denote a cumulative probability for the recurrence of a great earthquakes during a period between 0 , when the last earthquake occurred, and $t$ by $F(t)$. It is assumed that $F(t)$ is given as

$$
F(t)=1-\exp \left[-K t^{m+1} /(m+1)\right]
$$

in which $K$ and $m$ are parameters that can be determined from the actual data. How to determine these parameters having been given in the 1976 and other papers, no detailed account of obtaining $K$ and $m$ is given here.

Actual determination of $K$ and $m$ resulted in

$$
K=5.85 \times 10^{-8}, \quad m=2.75
$$

when $t$ is measured in units of years. With these parameters, the mean return period $T_{\mathrm{m}}$ and its standard deviation $\sigma_{T}$ are calculated as

$$
T_{\mathrm{m}}=109 \mathrm{yr}, \quad \sigma_{T}=33 \mathrm{yr} .
$$

These values do not differ much from those obtained in the previous analysis in which $T_{\mathrm{m}}=117 \mathrm{yr}$ and $\sigma=35 \mathrm{yr}$. They are also comparable with the values obtained by Utsu (1984) who gives $T_{\mathrm{m}}=117.1 \mathrm{yr}$ and $\sigma_{T}=21.2 \mathrm{yr}$.

With $F(t)$, which is called the cumulative probability, evaluated with the aid of the parameters thus obtained, we can evaluate a conditional probability $F S(t)$, which is called the hazard rate using the terminology of quality control engineering. On the condition that no earthquake occurs in the time range between 0 and $t$, the probability of having an earthquake between $t$ and $t+s$ is defined as $F S(t)$, which can be written as

$$
F S(t)=[F(t+s)-F(t)] /[1-F(t)] .
$$

Changes in $F(t)$ and $F S(t)$ as time goes on are calculated as shown in Fig. 3(a) in which $s=10 \mathrm{yr}$ is assumed. Time origin $t=0$ is taken at the year 1854 when we had the last Tokai earthquake. We now observe that $F(t)$ and $F S(t)$ steadily increase reaching fairly high values such as

$$
F(t)=0.868, \quad F S(t)=0.435
$$

at $t=146 \mathrm{yr}$ or in the year 2000 .

Although we do not know exactly how to appraise the probabilities thus obtained, the writer feels that these values are so high that we should be afraid of having a great Tokai earthquake within a 10-20 year's period from now.

\section{Probabilities Based on the Ultimate Displace- ment to Rupture}

As the writer did in the previous paper (Rikitake, 1976), simple multiplication of relative plate velocity by return period gives the ultimate displacement to rupture of the oceanic plate relative to the continental plate. In contrast to the previous paper, in which the writer relied on only one relative velocity, $6.0 \mathrm{~cm} / \mathrm{yr}$ say, at the plate boundary for the whole Tokai-Nankai zone, it now becomes possible to define more plausible velocities at the respective segments of the zone. Seno et al. (1993), who studied the motion of the Philippine Sea plate based on the earthquake slip vector data along the plate boundary, obtained the velocities as reproduced in Table 2 for each segment.

The velocity values cited in Table 2 appear to harmonize with the motion of the Philippine Sea plate as revealed by the VLBI observations on Chichi Jima Is. of Bonin Islands (Matsuzaka et al., 1991; Geographical Survey Institute, unpublished, 1997) and the GPS observation on 


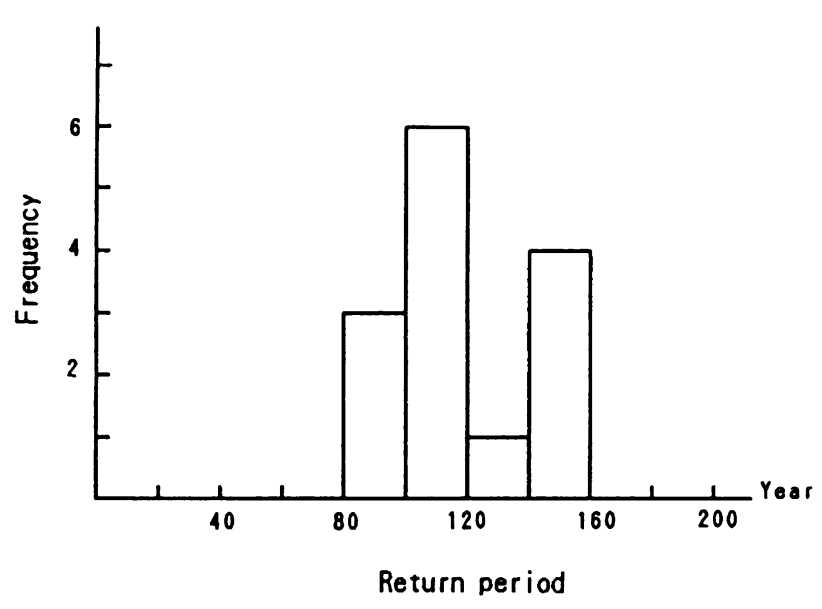

(a)

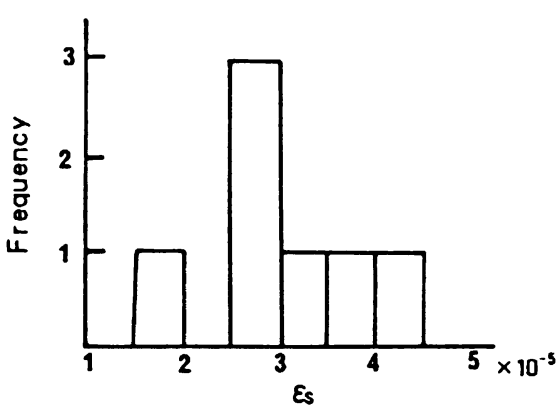

(c)

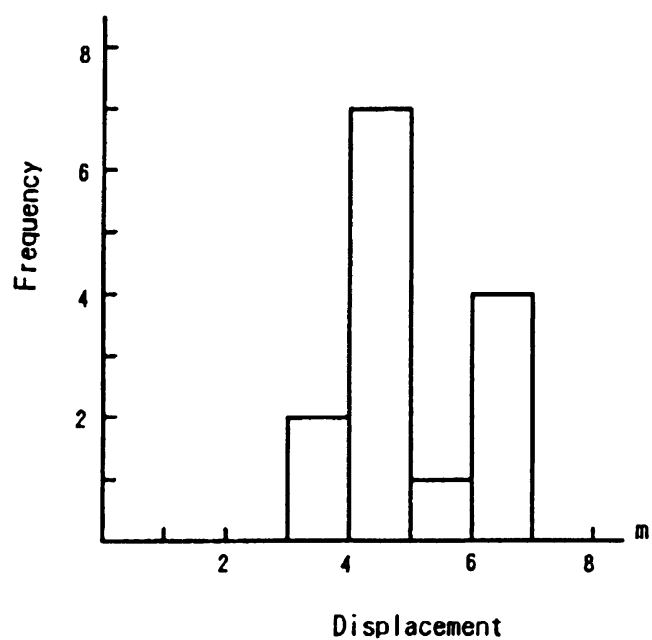

(b)

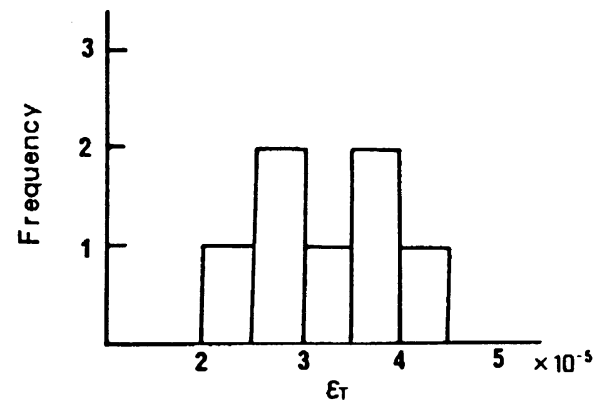

(d)

Fig. 2. Frequency histograms of (a) return period, (b) ultimate displacement, (c) ultimate crustal strain $\varepsilon_{\mathrm{S}}$ from SPM's and (d) ultimate crustal strain $\varepsilon_{\mathrm{T}}$ from TPM's as obtain for great earthquakes in the Tokai-Nankai zone. Detailed explanation of SPM and TPM are seen in the text.

Okino Torishima Is. (Parece Vela) (Kato et al., 1996), both situated in the middle of the plate.

Multiplying the return periods or earthquake intervals given in Table 1 by the corresponding relative velocities given in Table 2, we obtain 14 estimates of ultimate displacement for the Tokai-Nankai zone, the frequency histogram of which is shown in Fig. 2(b). It is of interest to compare the ultimate displacements thus obtained to the seismic slips actually obtained by analyzing seismic, geodetic and tsunami data because the slips are believed to take place as a crustal rebound associated with the fault rupture. Many studies have been conducted on the earthquake generation and fault mechanism of great earthquakes that occurred in the Tokai-Nankai zone by many authors (Fitch and Scholz, 1971; Kanamori, 1972; Ando, 1975, 1982; Inouchi and Sato, 1975; Aida, 1979, 1981a,b; Ishibashi, 1981; Kato, 1983; Miyashita, 1987). Although seismic slips obtained by these studies differ from study to study, the range of the slip amount seems to approximately agree with that of the ultimate displacement obtained here, i.e. 3-7 m. The slips derived from geodetic and tsunami studies appear somewhat larger than those from seismic records.
The frequency distribution shown in Fig. 2(b) is subjected to a Weibull distribution analysis in a way similar to that in Section 2 obtaining

$$
K=2.04 \times 10^{-3}, \quad m=3.73
$$

when the displacement is measured in units of meter. The mean ultimate displacement $D_{\mathrm{m}}$ and its standard deviations $\sigma_{D}$ are then obtained as

$$
D_{\mathrm{m}}=4.70 \mathrm{~m}, \quad \sigma_{D}=0.86 \mathrm{~m} .
$$

Dividing $D_{\mathrm{m}}$ by the relative velocity at Suruga Bay segment, $4.0 \mathrm{~cm} / \mathrm{yr}$ say, the mean return period there is estimated as $117 \mathrm{yr}$, a value almost agreeing with that obtained from the statistics of the simple recurrence model.

Making use of the parameters given in Eq. (6), the increase in the cumulative probability $F(t)$ and hazard rate $F S(t)$ at Suruga Bay segment can be calculated as time goes on in a manner similar to that in the last section as a function of time starting at the time of the 1854 Ansei Tokai earthquake as shown in Fig. 3(b). We see that the cumulative probability, and hazard rate reach the following values.

$$
F(t)=0.840, \quad F S(t)=0.491 \text {. }
$$




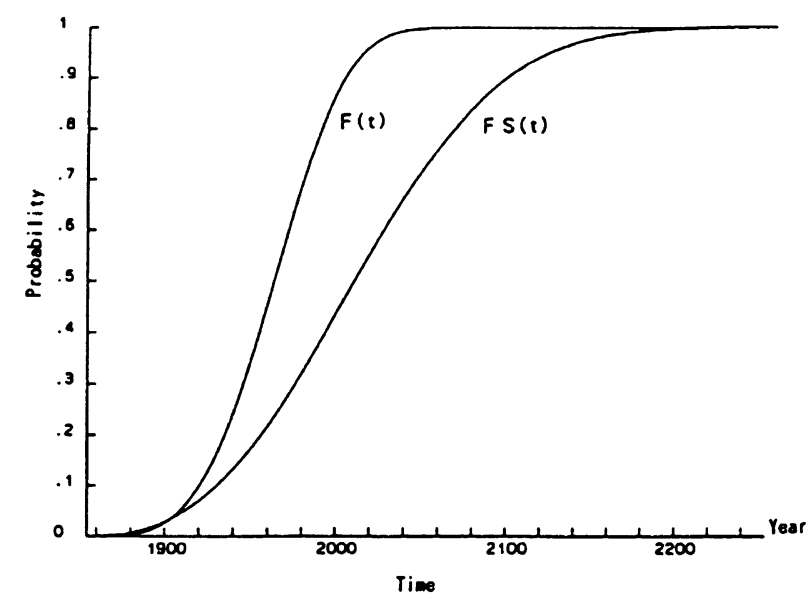

(a)

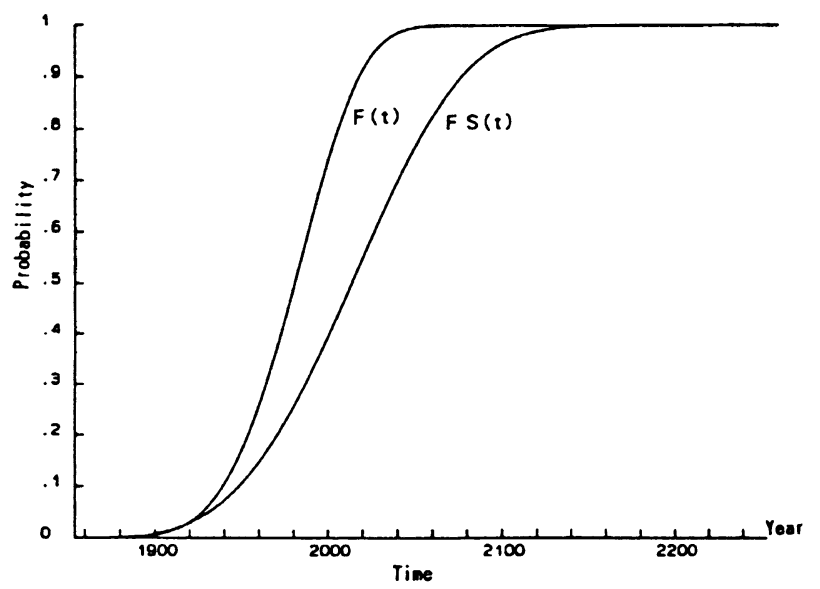

(c)

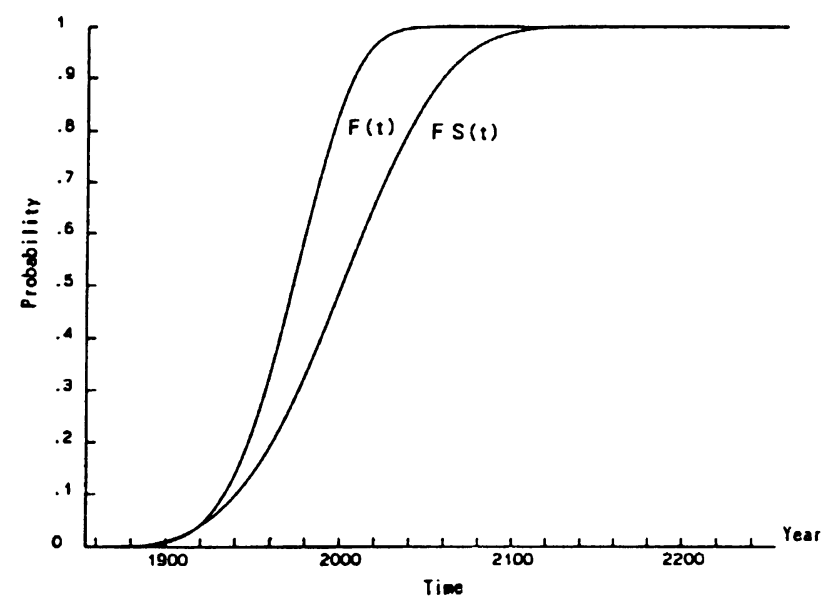

(b)

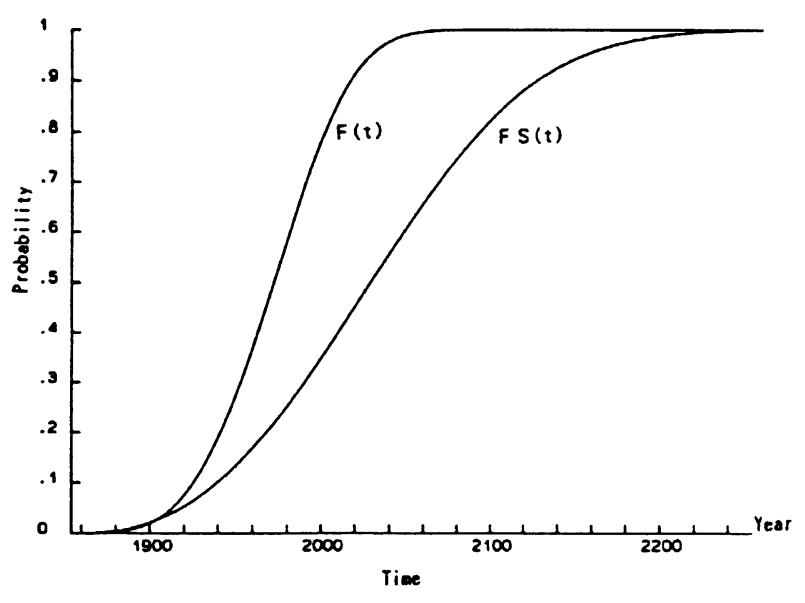

(d)

Fig. 3. Changes in the cumulative probability $F(t)$ and hazard rate $F S(t)$ for a great earthquake in the Tokai area as evaluated from (a) the simple recurrence tendency, (b) the ultimate displacement analysis of the Philippine Sea plate relative to the land plate, (c) the ultimate strain data based on SPM and (d) the similar data based on TPM.

It can be said that these are not much different from the values based on the simple recurrence statistics.

\section{Probabilities Estimated on the Basis of Quasi- Characteristic Models}

\subsection{Time-predictable or slip-predictable?}

Shimazaki and Nakata (1980) claimed that the recurrence pattern of great earthquakes in the Nankai zone can be accounted for by introducing the "time-predictable model" (TPM) as named by them. According to the model, the larger the slip is, the longer is the following inter-event period. Figure 4, which was presented by Shimazaki and Nakata (1980), shows the relation between the cumulative coseismic uplift at a port located at the tip of Muroto Peninsula, Shikoku Island and the date that indicates the occurrence times of the 1707, 1854 and 1946 Nankai earthquakes. It has been well known that the tip of the peninsula facing the Pacific Ocean is gradually subsiding during the interseismic periods, and that it jumps up at the times of earthquake occurrence.

A straight line, that best fits the three points at the bottom of each incremental step as denoted by A, B and C, is drawn in Fig. 4. The standard deviation of agreement is astonishingly small amounting only to $3.7 \mathrm{~cm}$. On the basis of such an analysis, it is supposed that the ever-increasing stress, probably due to the motion of Philippine Sea plate, tends to be released by a break at the land-sea plate boundary, when the stress reaches a certain constant value although the stress drop may differ from earthquake to earthquake. It is interesting to note that Shimazaki and Nakata (1980) indicate that the next Nankai earthquake is likely to occur in the year 2040.4 from such a TPM. The applicability of TPM to earthquake recurrences in other parts of Japan is also discussed by the above authors. Meanwhile, the validity of the model is also investigated for other areas of the world (e.g. Bufe et al., 1977; Sykes and Quittmeyer, 1981).

Looking at Fig. 4, we notice that even the points $\mathrm{A}^{\prime}, \mathrm{B}^{\prime}$ 
Table 2. Relative plate velocities at the Tokai-Nankai zone (Seno et al., 1993).

\begin{tabular}{cccccc}
\hline \multirow{2}{*}{ Zone } & \multicolumn{2}{c}{ Tokai zone } & & \multicolumn{2}{c}{ Nankai zone } \\
\cline { 2 - 3 } \cline { 5 - 6 } & $\begin{array}{c}\text { Suruga Bay } \\
(\text { Segment } 1)\end{array}$ & $\begin{array}{c}\text { Off Tokai } \\
\text { (Segment 2) }\end{array}$ & & $\begin{array}{c}\text { Off Kii Pen. } \\
\text { (Segment 3) }\end{array}$ & $\begin{array}{c}\text { Off Shikoku Is. } \\
\text { (Segment 4) }\end{array}$ \\
\hline $\begin{array}{c}\text { Relative velocity } \\
(\mathrm{cm} / \mathrm{yr})\end{array}$ & 4.0 & 4.1 & & 4.3 & 4.6 \\
\hline
\end{tabular}

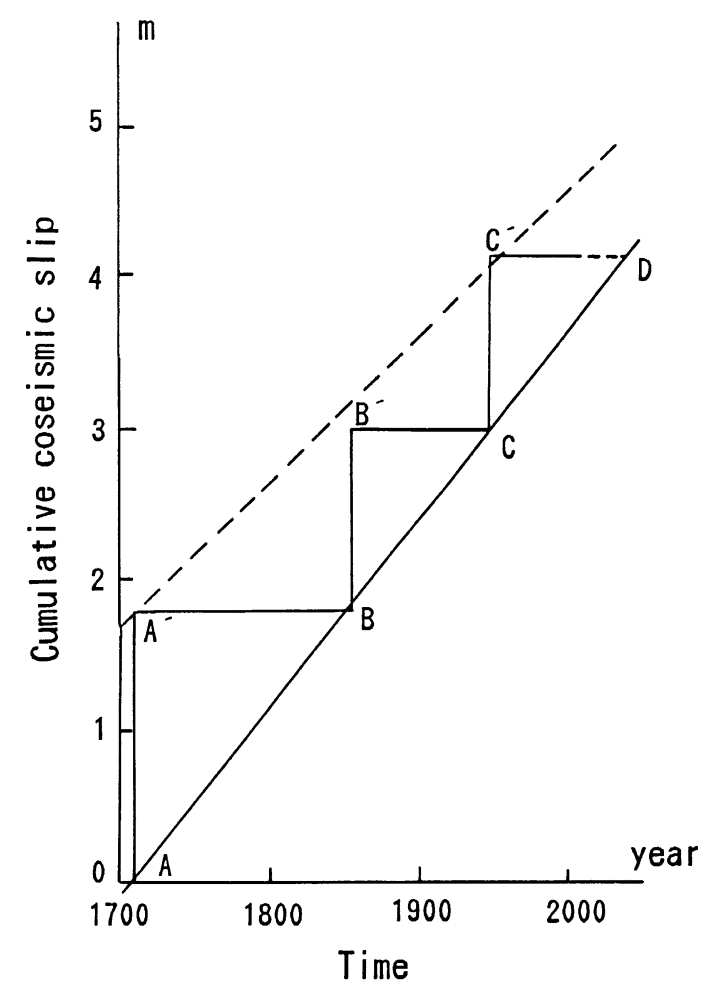

Fig. 4. Cumulative coseismic uplift associated with the three great earthquakes against date as obtained from the data observed at a port at the tip of the Muroto Peninsula, Shikoku Island (Shimazaki and Nakata, 1980).

and $\mathrm{C}^{\prime}$ at the top of each incremental step are getting higher roughly in a manner linearly increasing with time. In Fig. 4 is shown a dashed straight line that best fits the three points, the standard deviation amounting to $19.9 \mathrm{~cm}$, a somewhat larger value than that for the TPM. If one assumes that the period of interseismic quiescence is longer, the larger is the following earthquake, and the recurrence mode can be expressed by the dashed line in Fig. 4. Such a model is called the "slip-predictable model" (SPM) by Shimazaki and Nakata (1980). They pointed out that, if the stress level drops to a certain constant level at the time of each seismic break, such a occurrence pattern is accepted. But they insisted that a TPM should be adopted judging from the goodness of straight line fitting shown in Fig. 4.

It is certainly true that the TPM seems to fit the seismic slip-occurrence time relation in Fig. 4 better than the SPM. The standard deviation for the former amounts to only 3.7 $\mathrm{cm}$ in contrast to $19.9 \mathrm{~cm}$ for the latter. The present writer is, however, a little skeptical about the superiority of the former model to the latter one because of the accuracy of the seismic uplift data obtained from the historical record which is corrected for interseismic subsidence.

4.2 Use of seismic slips obtained from the tsunami study In contrast to the coseismic uplifts at a port located at Muroto Peninsula, Shikoku Island as referred to by Shimazaki and Nakata (1980), it is in this paper planned to make use of seismic slips at the actual fault model for the great earthquakes along the Tokai-Nankai zone in order to clarify the recurrence pattern there. Although seismic slips associated with faulting can best be obtained from an analysis of seismological data, such an approach is not possible for historical earthquakes. The writer thinks, therefore, that it is better to rely on seismic slip data obtained from the tsunami study (Aida, 1979, 1981a,b). It is believed that the source parameters obtained basing on tsunami study reflects the overall aspects of crustal movement over an area wider than that obtained from a seismic uplift only at one location as treated by Shimazaki and Nakata (1980) although an exact evaluation of the accuracy of deduced slip value is difficult to conduct.

Aida (1981b) proposed that the tsunami associated with the 1707 Hoei earthquake was excited by the fault movements, that took place almost simultaneously, schematically shown in Fig. 1. Summarizing the results obtained for the 1854 Ansei Tokai, 1944 Tonankai and 1946 Nankai earthquakes (Aida, 1979, 1981a,b), seismic slips at each segment along the Suruga-Nankai trough are obtained as given in Table 3.

Based on the slip amounts given in Table 3, cumulative slip vs. time diagrams are illustrated for the three segments, i.e. Off Shikoku Is., Off Kii Pen. and Off Tokai, respectively, as shown in Fig. 5. On the assumption that the SPM or TPM can be applied to the recurrence mode, the regression lines for the three segments are drawn as respectively shown in the figure with solid and dashed lines for the former and latter models in a manner similar to Fig. 4. The standard deviations for the respective fittings are estimated as shown in Table 4.

Unlike Shimazaki-Nakata's study (1980) for the Nankai zone, it is apparent in Fig. 5 and Table 4 that the fitting of SPM is better than that of TPM. However, the writer feels that no great difference in applicability can be seen between the two models. In light of the above analysis, it is doubtful to presume that the recurrence mode of great earthquakes in the Tokai-Nankai zone can be accounted for solely by TPM or SPM.

In spite of the uncertainty in the above, it is still of some interest to look at the occurrence epoch of the next great 
Table 3. Seismic slips for the respective fault segments at the times of great earthquakes in the Tokai-Nankai zone (Aida, 1979, 1981a,b) derived from tsunami data.

\begin{tabular}{ccccccc}
\hline & & \multicolumn{2}{c}{ Tokai zone } & & \multicolumn{2}{c}{ Nankai zone } \\
Earthquake & Year & $\begin{array}{c}\text { Suruga Bay } \\
\text { (Segment 1) }\end{array}$ & $\begin{array}{c}\text { Off Tokai } \\
\text { (Segment 2) }\end{array}$ & & $\begin{array}{c}\text { Off Kii Pen. } \\
\text { (Segment 3) }\end{array}$ & $\begin{array}{c}\text { Off Shikoku Is. } \\
\text { (Segment 4) }\end{array}$ \\
\hline Hoei & 1707.8 & $400 \mathrm{~cm}$ & $400 \mathrm{~cm}$ & & $560 \mathrm{~cm}$ & $700 \mathrm{~cm}$ \\
Ansei & 1855.0 & 400 & 400 & & 470 & 630 \\
Tonankai & 1944.9 & - & 215 & & - & - \\
Nankai & 1947.0 & - & - & 400 & 500 \\
\hline
\end{tabular}

OFF SHIKOKU IS.
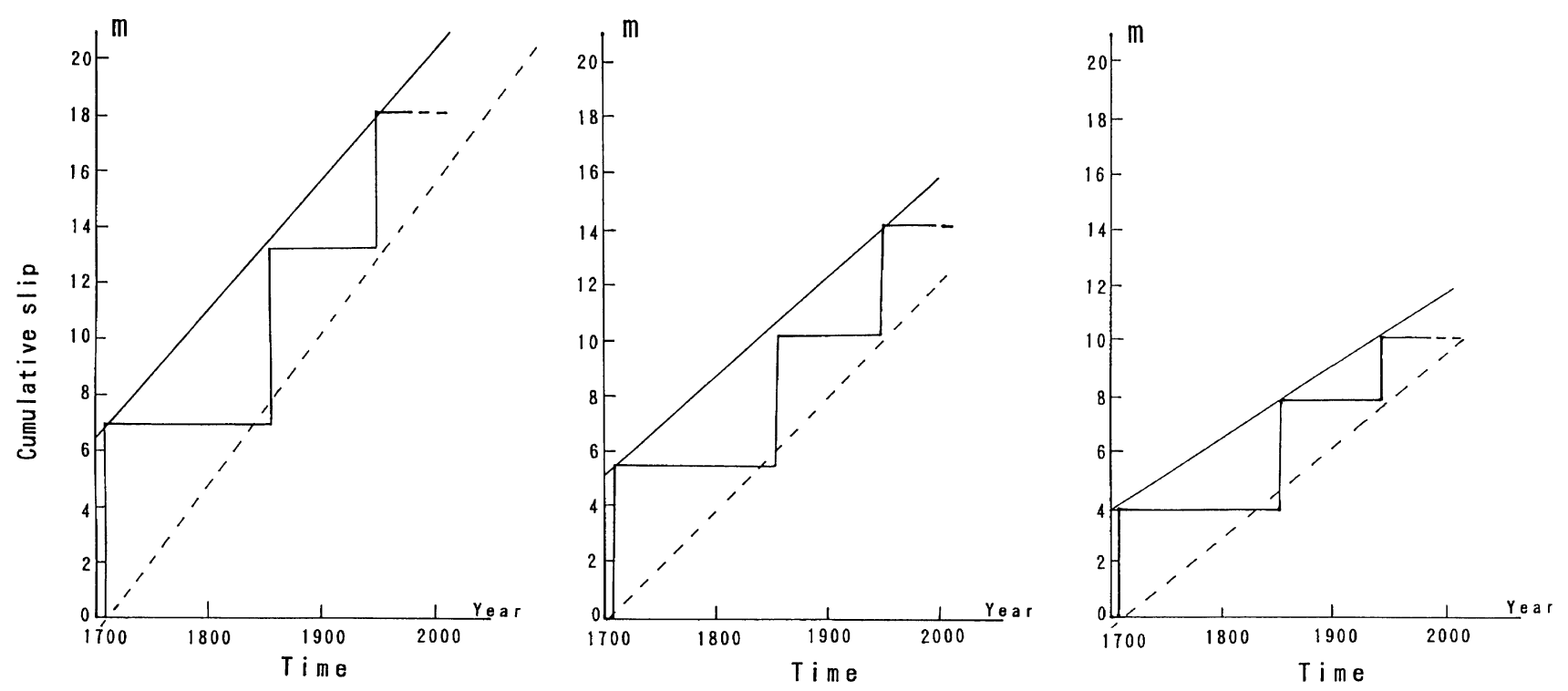

Fig. 5. Cumulative fault slips against date for the three segments in the Tokai-Nankai zone as obtained for the Hoei, Ansei and Tonankai-Nankai earthquakes. The fault slip data are given by Aida (1981b).

Table 4. Standard deviations for the model fittings.

\begin{tabular}{cccc}
\hline Model & $\begin{array}{c}\text { Off Tokai } \\
\text { (Segment 2) }\end{array}$ & $\begin{array}{c}\text { Off Kii Pen. } \\
\text { (Segment 3) }\end{array}$ & $\begin{array}{c}\text { Off Shikoku Is. } \\
\text { (Segment 4) }\end{array}$ \\
\hline SPM & $14.7 \mathrm{~cm}$ & $52.9 \mathrm{~cm}$ & $52.9 \mathrm{~cm}$ \\
TPM & 78.1 & 59.7 & 95.8 \\
\hline
\end{tabular}

earthquake, should the TPM be applicable. It is then estimated that a great earthquake would recur in 2047, 2048 and 2022 respectively at the Off Shikoku Is., Off Kii Pen. and Off Tokai segments. It should be borne in mind, however, a $t$-distribution analysis indicates that the ranges of occurrence time with $90 \%$ probability are so large that the credibility of the above occurrence times is not high. Although no such estimate can be made for the Suruga Bay area, it is probable that a large-scale crustal break in the area takes place in asso- ciation with the faulting off the Tokai zone on the assumption that the earthquake occurrence mode at the time of the 1854 Ansei event would repeat.

\subsection{Probabilities evaluated from crustal strain accumu- lation}

4.3.1 Crustal strain rate recently estimated for the source area of the coming Tokai earthquake

(1) Strain rate by classical geodetic means

Levelling surveys over the Tokai area have been intensively repeated along a variety of routes in the area in recent years (Geogr. Sur. Inst., 1996). Especially, surveys along the Kakegawa-Hamaoka route have been conducted four times a year since 1981, so that it is made clear that a remarkable subsidence of the area around Omaezaki Point relative to Kakegawa area amounting to about $17 \mathrm{~cm}$ took place during the 1962-1994 period. Basing on the results of these levelling surveys, the tilting rate in the SSE direction is estimated as $3.5 \times 10^{-7} / \mathrm{yr}$ for the 35 -year period between 1962 and 1997. Although the writer does not insist that the ground has 


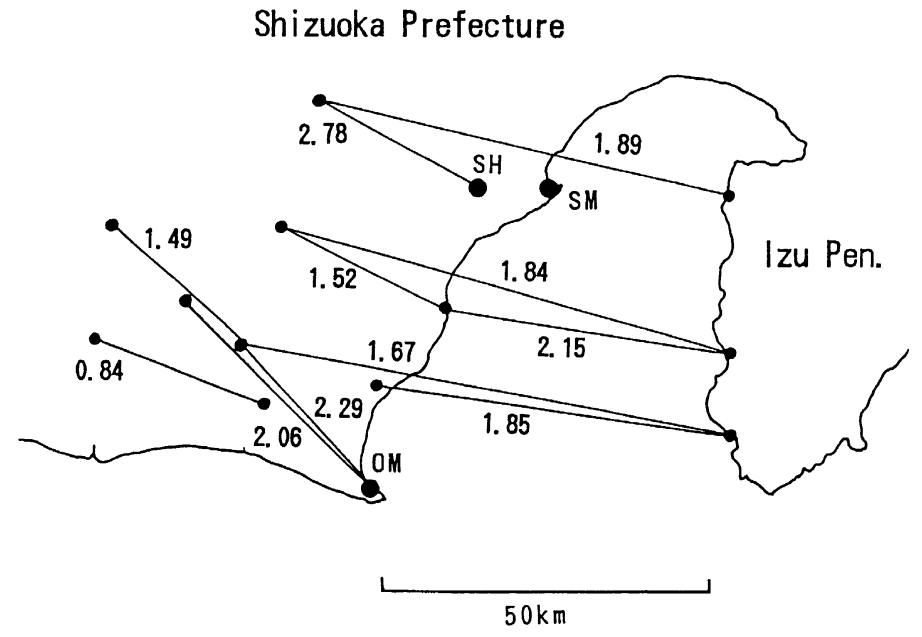

Pacific Ocean

Fig. 6. GPS stations and base-lines across and adjacent to Suruga Bay. The numerals labeled for each base-line indicate the strain rates of shortening in units of $10^{-7} / \mathrm{yr}$ obtained for respective lines during the 3-year period between March, 1994 and March, 1997. Abbreviations SH, SM and OM indicate the locations of Shizuoka, Shimizu and Omaezaki, respectively.

been inclined as an elastic body, the deformation rate thus estimated is compatible with that for the horizontal strain rate that will be mentioned in the following. From the resurveys of the first and second-order triangulation stations, horizontal strains accumulated on the west coast of Suruga Bay or the Shizuoka-Toyohashi area during the 89 year period between 1974 and 1885 were obtained by the Geographical Survey Institute (GSI) (1976). It is estimated that the yearly rate of maximum horizontal shear amounts to $3.2 \times 10^{-7} / \mathrm{yr}$ as the average for the 57 triangles.

Kimata (1992) and Nagoya University (1996) have been working on electro-optical distance measurement (EDM) for a number of base-lines in the Tokai area since 1978. A baseline of $18 \mathrm{~km}$ in length close to the Kakegawa-HamaokaOmaezaki area has been shortened with an yearly rate amounting to $1.5 \times 10^{-7} / \mathrm{yr}$ during the 18 year period between 1978 and 1996. The line strikes a direction almost parallel to that of the subduction of Philippine Sea plate.

(2) Strain rate by the recently-developed GPS system

GSI has long been working on distance measurements for many baselines around and across the Suruga Bay by means of electro-optical measuring devices. Such an EDM system has been replaced by GPS monitoring since the start of the 1990 's so that more frequent and accurate changes in length for many base-lines have now become available. Figure 6 shows the GPS stations in the Tokai area.

Among the changes in length between various combinations of stations as observed by GSI (Tada, 1997), let us pick up typical examples across the Suruga Bay and adjacent to the west of the bay as indicated in Fig. 6. The strain rates for each base-line are also shown in the figure. It is clearly noticed in the figure that all the base-lines are subjected to considerable contraction that is believed to be caused by the subduction of Philippine Sea plate in the NW direction. It is interesting to note that no marked differences in the strain rates are observed between the base-lines across the Suruga

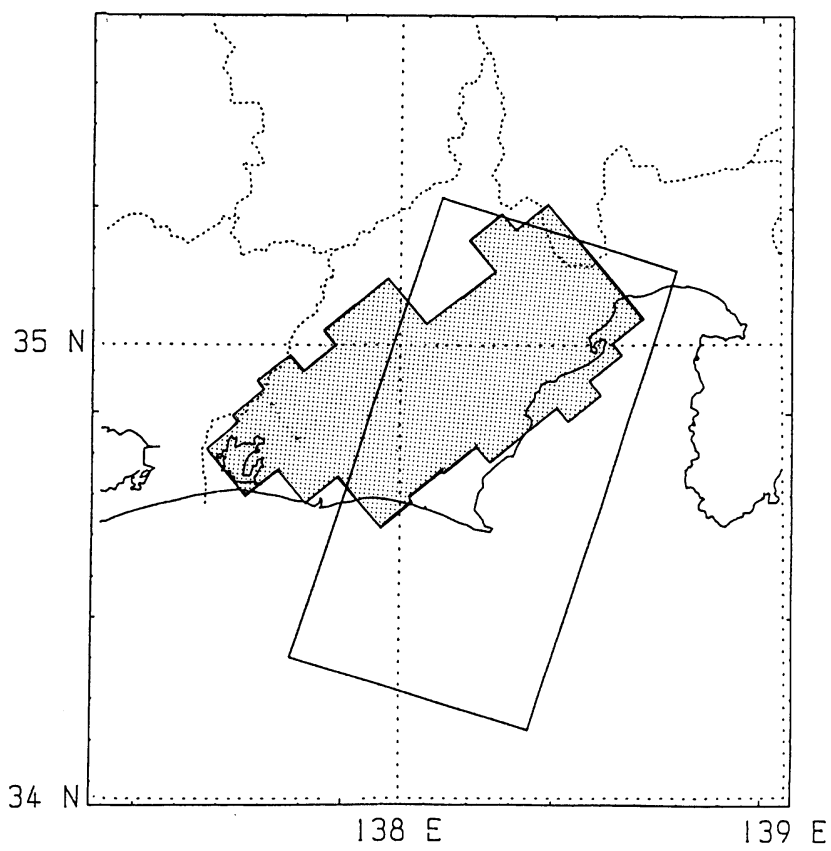

Fig. 7. Horizontal projections of supposed source area of the coming Tokai earthquake as shown by the rectangle (Ishibashi, 1981). The shaded area indicates the portion of down-going slab surface firmly coupled with the upper crust obtained by Matsumura (Natl. Res. Inst. Earth Sci. Disast. Prev., 1994).

Bay and the adjacent land area.

(3) Anticipated source area of the coming Tokai earthquake

It has so far been supposed that a fault of which the horizontal projection is shown with a rectangle in Fig. 7, would break at the time of the next Tokai earthquake (Ishibashi, 1981). The upper end of the fault agreeing with the Suruga trough, the fault plane is believed to be dipping towards the 
Table 5. Source parameters and other elements related to the earthquake faults in each segment. The definitions of each mark parameter are given in the text.

\begin{tabular}{|c|c|c|c|c|c|c|c|c|c|c|}
\hline Segment & Earthquake & $i$ & $\begin{array}{c}L_{i} \\
(\mathrm{~km})\end{array}$ & $\begin{array}{c}W_{i} \\
(\mathrm{~km})\end{array}$ & $\begin{array}{c}U_{i} \\
(\mathrm{~cm})\end{array}$ & $\begin{array}{l}\Delta T_{i} \\
(\mathrm{yr})\end{array}$ & $\begin{array}{l}\Delta T_{i} v \\
(\mathrm{~cm})\end{array}$ & $\begin{array}{l}\Delta U_{i} \\
(\mathrm{~cm})\end{array}$ & $\begin{array}{c}\varepsilon_{\mathrm{S}, i} \\
\left(10^{-5}\right)\end{array}$ & $\begin{array}{c}\varepsilon_{\mathrm{T}, i} \\
\left(10^{-5}\right)\end{array}$ \\
\hline (1) Suruga Bay & Hoei & 1 & 115 & 70 & 400 & - & - & - & - & - \\
\hline$v=4.0 \mathrm{~cm} / \mathrm{yr}$ & Ansei & 2 & 115 & 70 & 400 & 147 & 588 & 0 & 4.2 & 4.2 \\
\hline (2) Off Tokai & Hoei & 1 & 150 & 100 & 400 & - & - & - & - & - \\
\hline \multirow[t]{2}{*}{$v=4.1 \mathrm{~cm} / \mathrm{yr}$} & Ansei & 2 & 150 & 100 & 400 & 147 & 603 & 0 & 3.0 & 3.0 \\
\hline & Showa & 3 & 154 & 67 & 215 & 90 & 370 & 185 & 2.8 & 2.8 \\
\hline (3) Off Kii Pen. & Hoei & 1 & 150 & 70 & 560 & - & - & - & - & - \\
\hline \multirow[t]{2}{*}{$v=4.3 \mathrm{~cm} / \mathrm{yr}$} & Ansei & 2 & 150 & 70 & 470 & 147 & 632 & 90 & 3.5 & 3.5 \\
\hline & Showa & 3 & 150 & 70 & 400 & 92 & 396 & 160 & 2.8 & 3.5 \\
\hline (4) Off Shikoku Is. & Hoei & 1 & 140 & 80 & 700 & - & - & - & - & - \\
\hline \multirow[t]{2}{*}{$v=4.6 \mathrm{~cm} / \mathrm{yr}$} & Ansei & 2 & 150 & 120 & 630 & 147 & 676 & 70 & 2.8 & 2.8 \\
\hline & Showa & 3 & 120 & 120 & 500 & 92 & 423 & 200 & 1.8 & 2.1 \\
\hline
\end{tabular}

NW direction with an angle of 30 degrees or so.

Recent analysis of the source mechanisms of microearthquakes by S. Matsumura (e.g. Natl. Res. Inst. Earth Sci. Disast. Prev., 1994) makes it clear, however, that the upper surface of the subducting slab, which is shown by the shaded area in Fig. 7, is firmly coupled with the upper crust. If so, the area over the coupled portion of Philippine Sea plate would play an important role of earthquake generation in case the anticipated Tokai earthquake should occur. It is therefore likely that the main source area would lie beneath the Shizuoka Prefecture covering the Shizuoka-Hamamatsu zone.

(4) Mean strain rate over the source area

Making use of the strain rates in the previous paragraphs; i.e. the rate for the 57 geodetic triangles to the west of Suruga Bay, that for a base-line measured by the Nagoya University and those from the 6 GPS base-lines given in Fig. 6, the average strain rate over the supposed source area is estimated. As a strain rate value obtained from surveys covering a long period is more reliable than that for a short period (Rikitake, 1983), the weighted mean strain rate with weights proportional to survey interval is calculated obtaining $2.39 \times 10^{-7} / \mathrm{yr}$ with a standard deviation amounting to $0.53 \times 10^{-7} / \mathrm{yr}$.

4.3.2 Ultimate strain to rupture in the Tokai area Rikitake (1975), who analyzed crustal movements associated with an earthquake showed that ultimate strain to rupture of the earth's crust can well be approximated by a Weibull distribution. The analysis of occurrence frequency of events indicates that the cumulative probability $F(\varepsilon)$ of an earthquake occurring in a strain range $0 \sim \varepsilon$ is given by

$$
F(\varepsilon)=1-\exp \left[-K \varepsilon^{m+1} /(m+1)\right]
$$

where $\varepsilon$ is the crustal strain. $K$ and $m$ are parameters determined from the data.

It appears that the tectonic and geological condition is different from region to region, so that the above parameters should be determined for the area concerned. For such a purpose the only way is to rely on the data of historical earthquakes. Although seismic slips $(U)$ in association with the great earthquakes in the Tokai-Nankai zone are given in Table 3, we here refer to other source parameters such as length $(L)$ and width $(W)$ of the source fault. These parameters for the 1707 Hoei earthquake are, for example, shown in Fig. 1 and summarized for the four segments along the Suruga-Nankai trough in Table 5 along with some other elements with respect to each earthquake.

In the table, $\Delta T$ is the recurrence interval, so that $\Delta T v$ indicates the displacement of the plate that takes place during the period between successive earthquakes, $v$ being the plate velocity as before. $U, L, W$ and $\Delta T$ in the table are specified with suffix $i(=1,2,3)$. The Hoei, Ansei and Showa events correspond to $i=1,2$ and 3 .

If we simply assume that all the stress accumulated is released at the time of earthquake occurrence and that the stress starts to be accumulated after that because of the plate motion, $\Delta T_{i} v$ is nothing but the ultimate displacement. Denoting the length of area where such a displacement predominates by $D_{i}$, the ultimate strain can be expressed by

$$
\varepsilon_{\mathrm{S}, i}=\Delta T_{i} v / D_{i} .
$$

It should be noted that such an idea is based on the SPM as discussed before.

In contrast to such a standpoint relying on an SPM, let us take a standpoint based on a TPM for which the ultimate displacement is given by $\Delta T_{i} v+\Delta U_{i-1}$, where $\Delta U_{i-1}$ is the residual displacement for the last earthquake. Although no exact value of $\Delta U_{i}$ is known, we may assume that $\Delta U_{i}$ is given by the difference in the displacement between that at the time of the Hoei earthquake, which is the largest shock in the seismic zone, and that of each earthquake. $\Delta U_{i}$ obtained with such an assumption is given in Table 5 for each earthquake. We may then define the ultimate strain by

$$
\varepsilon_{\mathrm{T}, i}=\left(\Delta T_{i} v+\Delta U_{i-1}\right) / D_{i}
$$


Table 6. Parameters for the ultimate strain $(\varepsilon)$ and analysis. Mean values of strain and their standard deviations are also shown for the two models.

\begin{tabular}{ccccc}
\hline Model & $K$ & $m$ & $\begin{array}{c}\text { Mean value of } \\
\varepsilon\left(10^{-5}\right)\end{array}$ & $\begin{array}{c}\text { Standard deviation } \\
\left(10^{-5}\right)\end{array}$ \\
\hline TPM & 0.0173 & 3.74 & 2.99 & 0.71 \\
SPM & 0.0528 & 2.75 & 2.81 & 0.76 \\
\hline
\end{tabular}

basing on the standpoint of TPM.

No exact value of $D_{i}$ is known. But, as discussed by Rikitake (1976), the amount of crustal deformation associated with an earthquake steeply decreases with the distance from the fault for the immediate neighbourhood of trace and then tails off rather gradually as the distance increases. Taking into the distance between the anticipated source area and fault trace for the coming Tokai earthquake, the writer tentatively assumes that $D_{i}$ is given by approximately $2 W_{i}$. Such an assumption seems likely to hold good approximately for the geodetic result in association with plate-boundary earthquakes such as the Kanto (e.g. Ando, 1971) and Nankai (e.g. Sato, 1973) earthquakes.

With the values of $D_{i}$ thus evaluated, $\varepsilon_{\mathrm{S}, i}$ and $\varepsilon_{\mathrm{T}, i}$ are calculated and shown in Table 5 for each case in the respective segments. In Figs. 2(c) and 2(d) are shown the frequency histograms of $\varepsilon_{\mathrm{S}, i}$ and $\varepsilon_{\mathrm{T}, i}$ which are subjected to Weibull distribution analyses although the number of data is not large.

Parameters determined from these analyses, i.e. $K$ and $m$, are shown in Table 6 along with the mean values of $\varepsilon_{\mathrm{S}}$ and $\varepsilon_{\mathrm{T}}$ and their standard deviations. We see no marked difference in the parameters between the SPM and TPM in the table.

4.3.3 Probabilities based on the strain rate and strain accumulation Relying on the strain rate and the parameters related to ultimate strain respectively evaluated in Subsections 4.3.1 and 4.3.2, cumulative probabilities $F(t)$ and hazard rates $F S(t)$ for ten-year period are calculated for the Suruga Bay area or segment 1. It is assumed that all the strain so far accumulated was released at the time of the 1854 Ansei earthquake. Such an assumption may hold good even for the TPM because $\Delta U_{2}=0$ as can be seen in Table 5 .

$F(t)$ and $F S(t)$ thus calculated by making use of Eqs. (1) and (4) increase as time goes on in a manner shown in Figs. 3(c) and 3(d) respectively for the SPM and TPM. It is estimated that $F(t)$ reaches fairly high values amounting to 0.782 and 0.745 by the year 2000 respectively for the SPM and TPM. Meanwhile $F S(t)$ at the same epoch amount to 0.349 and 0.395 for the respective models. The significance of these probability values thus evaluated will be discussed in the following section.

\section{Discussion and Conclusions}

In view of the development of paleoseismology, plate tectonics, tsunami study, microearthquake investigation, and geodetic survey method developed in recent years, it is undertaken in this paper to revise probability evaluation of the recurrence of the great Tokai earthquake which has so far been a nation-wide concern in Japan.

First of all, probability due to simple recurrence tendency is evaluated taking the newly-identified occurrences of great earthquake in the Tokai-Nankai zone into account, the new evidence having been brought to light by means of ground liquefaction traces in the past. In the next place, the ultimate displacement of the ocean plate relative to the land plate is reestimated based on the newly-determined plate velocity. Such a study resulted in an improved frequency distribution of ultimate displacement, and so the Weibull distribution analysis of the distribution can lead us to evaluate the revised probability of earthquake occurrence in the area studied.

It is interesting to study the validity of the concept of characteristic earthquake by means of the fault slip amount which can be surmised from the tsunami study. In this paper, whether or not the idea of TPM (time-predictable model) or SPM (slip-predictable model) proposed by Shimazaki and Nakata (1980) works well is tested by the amounts of fault slip as made clear by the tsunami study. It appears, unlike Shimazaki and Nakata's study, that the SPM may a little better account for the fault slip vs. time interval relations of the great earthquakes in the Tokai-Nankai zone than the TPM.

On the other hand, the likely source area of future earthquake as indicated by a portion of the slab surface of downgoing plate firmly coupled with the upper crust has been brought out by microearthquake observation in recent years. Meanwhile, the crustal strain rate over the area has become monitored very precisely by means of newly-developed GPS net in addition to the classical geodetic surveys. Taking these new achievements into account, statistics of ultimate strain to rupture combined with the newly-obtained strain rate leads us to a reevaluation of earthquake occurrence probability for which two cases relying on the SPM and TPM are considered.

In Table 7 are summarized the probabilities of occurrence of the great Tokai earthquake at the epoch of the year 2000. Cumulative probabilities $F(t)$ and hazard rates $F S(t)$ evaluated on the basis of the above four models are given in the table.

Rikitake (1986) estimated hazard rate for the year 2000 of the Tokai earthquake basing on the then-available data reaching values amounting to 0.41 and 0.35 respectively for the simple recurrence model and SPM. Comparing these values to those in Table 7, the writer does not see much difference in the probability values between the 1986 and present evaluations.

It may be said, therefore, that the probability of a great earthquake to occur in the Tokai area within a ten-year period from the year 2000 amounts to $0.35-0.45$ as far as we rely on the techniques available at present.

It is not very clear how to appraise the probability values thus evaluated. But the writer feels that the probability in the Tokai area is substantially higher than those for other areas in Japan, where we may expect the occurrence of a great earthquake having a magnitude of 8 or over. Such a view certainly suggests the possibility of having a great earthquake in the Tokai area in the near future.

Although the probabilities for future occurrence of a great earthquake in the Tokai area thus evaluated have to inevitably rely on somewhat inaccurate data and models, it is important that all the probabilities based on different approaches indicate high values amounting to 35-45 percent for a ten-year period from the year 2000 . The fact should seriously be rec- 
Table 7. Cumulative probability $F(t)$ and hazard rate $F S(t)$ of the Tokai earthquake occurrence as evaluated for the year 2000. Four different approaches mentioned in the text are made use of.

\begin{tabular}{lcccc}
\hline & \multirow{2}{*}{ Simple recurrence model } & Ultimate displacement & \multicolumn{2}{c}{ Ultimate strain } \\
\cline { 4 - 5 } & & & SPM & TPM \\
\hline Cumulative probability* & 0.868 & 0.840 & 0.782 & 0.745 \\
Hazard rate $^{* *}$ & 0.435 & 0.491 & 0.349 & 0.395 \\
\hline
\end{tabular}

\footnotetext{
*The probability for the Tokai earthquake occurring in a period between 1854 and 2000 2000 .

* The probability of earthquake occurrence during 2001-2010 on the condition that the earthquake does not occur before the year
}

ognized by the earthquake preparedness agencies which are responsible for mitigation of earthquake damage in the Tokai area.

Acknowledgments. The writer is thankful to two anonymous referees whose comments and suggestions are highly useful for revising the paper.

\section{References}

Aida, I., A source model of the tsunami accompanying the Tonankai earthquake of 1944, Bull. Earthq. Res. Inst., Univ. Tokyo, 54, 329-341, 1979 (in Japanese).

Aida, I., Numerical experiments of historical tsunamis generated off the coast of the Tokaido district, Bull. Earthq. Res. Inst., Univ. Tokyo, 56, 367-390, 1981a (in Japanese).

Aida, I., Numerical experiments for the tsunamis generated off the coast of the Nankaido district, Bull. Earthq. Res. Inst., Univ. Tokyo, 56, 713-730, $1981 b$ (in Japanese).

Ando, M., A fault-origin model of the great Kanto earthquake of 1923 as deduced from geodetic data, Bull. Earthq. Res. Inst., Univ. Tokyo, 49, 19-32, 1971.

Ando, M., Source mechanisms and tectonic significance of historical earthquakes along the Nankai trough, Japan, Tectonophysics, 27, 119-140, 1975.

Ando, M., A fault model of the 1946 Nankaido earthquake derived from tsunami data, Phys. Earth Planet. Inter, 28, 320-336, 1982.

Bufe, C. G., P. W. Harsh, and R. O. Burford, Steady-state seismic slip-a precise recurrence model, Geophys. Res. Lett., 4, 91-94, 1977.

Fitch, T. J. and C. H. Scholz, Mechanism of underthrusting in southwest Japan: A model of convergent plate interactions, J. Geophys. Res., 76, 7260-7292, 1971.

Geogr. Sur. Inst., Horizontal strains in Tokai district, Rep. Coord. Comm. Earthq. Predict., 15, 103-105, 1976 (in Japanese).

Geogr. Sur. Inst., Crustal deformations in the Tokai district, Rep. Coord. Comm. Earthq. Predict., 56, 346-366, 1996 (in Japanese).

Inouchi, N. and H. Sato, Vertical crustal deformation accompanied with the Tonankai earthquake of 1944, Bull. Geogr. Sur. Inst., 21, 10-18, 1975.

Ishibashi, K., Specification of a soon-to-occur seismic faulting in the Tokai district, central Japan, based upon seismotectonics, in Earthquake Prediction-An International Review, Maurice Ewing Series 4, pp. 297 344, Am. Geophys. Union, 1981.

Kanamori, H., Tectonic implication of the 1944 Tonankai and the 1946 Nankaido earthquakes, Phys. Earth Planet. Inter., 5, 129-139, 1972.

Kato, T., High-angle reverse faulting associated with the 1946 Nankaido earthquake, Tectonophysics, 96, 31-44, 1983.

Kato, T., Y. Kotake, T. Chahin, Y. Iimura, S. Miyazaki, T. Kanazawa, and K. Suyehiro, An estimate of the Philippine Sea plate motion derived from the global positioning system observation at Okino Torishima, Japan, $J$.
Geod. Soc. Jpn., 42, 233-243, 1996

Kimata, F., Strain event in 1985-1987 in the Tokai region, Central Japan, J. Phys. Earth, 40, 585-599, 1992.

Matsuzaka, S., M. Tobita, Y. Nakahori, J. Amagi, and Y. Sugimoto, Detection of Philippine Sea plate motion by Very Long Baseline Interferometry, Geophys. Res. Lett., 18, 1417-1419, 1991.

Miyashita, K., A model of plate convergence in southwest Japan, inferred from leveling data associated with the 1946 Nankaido earthquake, J. Phys. Earth, 35, 449-467, 1987.

Nagoya University, Time series of baseline lengths at Tokai region by EDM in the period of 1978-1996/4, Rep. Coord. Comm. Earthq. Predict., 56 370-372, 1996 (in Japanese).

Natl. Res. Inst. Earth Sci. Disast. Prev., Focal zone of the next Tokai earthquake inferred from the seismic activity in the Philippine Sea slab, Rep. Coord. Comm. Earthq. Predict., 51, 498-505, 1994 (in Japanese).

Rikitake, T., Statistics of ultimate strain of the earth's crust and probability of earthquake occurrence, Tectonophysics, 26, 1-21, 1975.

Rikitake, T., Recurrence of great earthquakes at subduction zones, Tectonophysics, 35, 335-362, 1976.

Rikitake, T., Probability of a great earthquake to recur off the Pacific coast of Central Japan, Tectonophysics, 42, T43-T51, 1977.

Rikitake, T., Active fault and crustal strain, Earthq. Predict. Res., 3, 167189, 1983.

Rikitake, T., Earthquake Precursors, 232 pp., Univ. Tokyo Press, 1986 (in Japanese).

Sangawa, A., Evidence of paleoearthquakes found out in some archaeological sites, J. Geogr., 99, 51-62, 1990 (in Japanese).

Sangawa, A., Jishin Kokogaku (Seismological Archaeology), 251 pp., Chuo Koronsha, 1992 (in Japanese).

Sato, H., A study of horizontal movement of the earth crust associated with destructive earthquakes in Japan, Bull. Geogr. Sur. Inst., 19, 89-130, 1973.

Seno, T., S. Stein, and A. E. Gripp, A model for the motion of the Philippine Sea plate consistent with NUVEL-1 and geological data, J. Geophys. Res., 98, 17941-17948, 1993.

Shimazaki, K. and T. Nakata, Time-predictable recurrence model for large earthquakes, Geophys. Res. Lett., 7, 279-282, 1980.

Sykes, L. R. and R. C. Quittmeyer, Repeat times of great earthquakes along simple plate boundaries, in Earthquake Prediction-An International Review, Maurice Ewing Series 4, pp. 217-247, Am. Geophys. Union, 1981

Tada, T., Recent crustal movement (I) over the Tokai area, Debate about the Tokai Earthquake, Association for the Development of Earthquake Prediction, pp. 103-124, 1997 (in Japanese).

Utsu, T., Estimation of parameters for recurrence models of earthquakes, Bull. Earthq. Res. Inst., Univ. Tokyo, 59, 53-66, 1984.

T. Rikitake (e-mail: rikitake@8f.adep.or.jp) 